\title{
Consumo de nutrientes, comportamento ingestivo e parâmetros fisiológicos de ovinos alimentados com volumoso extrusado contendo diferentes aditivos
}

\author{
Karla Alves Oliveira ${ }^{1 *}$; Tamires Soares de Assis ${ }^{2}$; Luciano Fernandes Sousa ${ }^{3}$; Marco Tulio Santos Siqueira ${ }^{4}$; \\ Amanda Menezes de Souza ${ }^{5}$; Gilberto de Lima Macedo Júnior ${ }^{6}$
}

DOI: https://doi.org/10.35699/2447-6218.2020.20606

\begin{abstract}
Resumo:
Avaliou-se a utilização do volumoso extrusado contendo diferentes aditivos sobre parâmetros nutricionais e fisiológicos de ovinos. Foram utilizadas 20 ovelhas não gestantes, adultas, com peso médio de $68 \mathrm{~kg}$. Os animais receberam cinco tratamentos contendo volumoso extrusado com diferentes aditivos (óleos essenciais, virginiamicina, tanino, levedura inativa não purificada e levedura inativa purificada). O delineamento foi em blocos casualizados, com cinco tratamentos e oito repetições. As médias foram comparadas pelo teste SNK com nível de significância de 5\% de probabilidade. Avaliou-se o consumo e digestibilidade da matéria seca e fibra em detergente neutro, consumo de matéria seca em função de peso corporal e metabólico, comportamento ingestivo, parâmetros fisiológicos e pH ruminal. Não foram observadas diferenças estatísticas em função da inclusão de aditivos para consumo e digestibilidade da matéria seca, fibra em detergente neutro e digestibilidade de fibra em detergente neutro, comportamento ingestivo, eficiência de alimentação, frequência respiratória, frequência cardíaca, temperatura retal e pH ruminal. O tratamento com levedura purificada apresentou o maior consumo de matéria seca em função do peso corporal e metabólico. Houve efeito quadrático sobre o pH em função do horário de coleta, sendo menor nas primeiras 4 horas após a refeição, ou seja, o uso de aditivos apresenta resposta positiva na fermentação ruminal devido ao reestabelecimento do valor de $\mathrm{pH}$. O uso de aditivos influenciou o consumo de matéria seca pelas ovelhas, sendo este maior quando utilizado o aditivo levedura inativa purificada. Os aditivos foram eficientes também na manutenção do pH ruminal e digestibilidade aparente da matéria seca.
\end{abstract}

Palavras-chaves: Leveduras. Óleos essenciais. Ruminantes. Tanino. Virginiamicina.

\section{Nutrient intake, ingestive behavior and physiological parameters of sheep fed with extruded roughage with different additives}

\author{
Abstrat:

\footnotetext{
${ }^{1}$ Universidade Estadual Paulista "Júlio de Mesquita Filho". Jaboticabal, SP. Brasil.

https://orcid.org/0000-0002-7792-2615

${ }^{2}$ Universidade Federal de Uberlândia. Uberlândia, MG. Brasil.

https://orcid.org/0000-0002-9798-9956

3Universidade Federal de Tocantins.Palmas, TO. Brasil.

https://orcid.org/0000-0002-6072-9237

${ }^{4}$ Universidade Federal de Uberlândia. Uberlândia, MG. Brasil. https://orcid.org/0000-0002-2098-8568

${ }^{5}$ Universidade Federal de Uberlândia. Uberlândia, MG. Brasil. https://orcid.org/0000-0003-1532-2005

${ }^{6}$ Universidade Federal de Uberlândia. Uberlandia, MG. Brasil. https://orcid.org/0000-0001-5781-7917

*Autor para correspondência: karla.alves.oliveira@hotmail.com
}

The objective of this work was to evaluate the use of extruded roughage containing different additives, on nutritional and physiological parameters of sheep. Twenty non - pregnant ewes were used, adults with an average weight of 68 $\mathrm{kg}$. The animals received five treatments containing extruded roughage with different additives (essential oils, virgi-

Recebido para publicação em 13 de Maio de 2020. Aceito para publicação 25 de Agosto de 2020 e-ISSN: 2447-6218 / ISSN: 2447-6218. Atribuição CC BY. 
niamycin, tannin, unpurified inactive yeast and purified inactive yeast). The experimental design was a randomized block design with five treatments and eight replications. The means were compared by the SNK test with significance level of 5\% of probability. The following variables were evaluated: dry matter and neutral detergent fiber intake and digestibility; dry matter intake as a function of body and metabolic weight; ingestive behavior; physiological parameters and ruminal pH. No statistical difference was observed due to the inclusion of additives, for dry matter and neutral detergent fiber intake and digestibility, ingestive behavior, feed efficiency, respiratory rate, heart rate, rectal temperature and ruminal $\mathrm{pH}$. The treatment with purified yeast showed the highest dry matter intake as a function of body and metabolic weight. There was a quadratic effect on $\mathrm{pH}$ depending on the time of collection, being lower in the first 4 hours after the meal, that is, the use of additives shows a positive response in rumen fermentation due to the reestablishment of the $\mathrm{pH}$ value. The use of additives influenced the dry matter intake by the sheep, which is greater when the additive inactive purified yeast is used. The additives were also efficient in maintaining ruminal $\mathrm{pH}$ and apparent dry matter digestibility.

Keyword: Essencial oils. Ruminants. Tannin. Virginiamycin. Yeast.

\section{Introdução}

A utilização dos aditivos na nutrição de ruminantes é cada vez mais pesquisada, uma vez que esses atuam por diferentes mecanismos, que podem modificar a fermentação ruminal, causar a estabilização do meio e proteger o trato gastrointestinal de agentes patogênicos, o que aumenta, desta forma, a degradabilidade ruminal dos nutrientes e reduz o desperdício (Souza e Rodrigues, 2012).

Os aditivos são suplementos alimentares que podem contribuir para o melhor desempenho de animais confinados, uma vez que esse contribui para a manutenção do $\mathrm{pH}$ e da saúde ruminal. Ao longo do dia o pH apresenta flutuações em função da dieta utilizada, da forma física do alimento, do tamanho da partícula e do processamento. $\mathrm{O}$ alimento extrusado tem sido utilizado na alimentação de ruminantes, com o intuito de aumentar $\mathrm{o}$ aproveitamento do alimento pelos microrganismos e também facilitar o manejo alimentar, visto que o processo de extrusão aumenta a digestibilidade dos alimentos e a destruição de patógenos. O volumoso extrusado é uma alternativa de alimento fibroso para ruminantes, sendo este produzido da parte aérea de gramíneas após o processo de extrusão, podendo assim melhorar a digestibilidade e aumentar eficiência produtiva animal (Oliveira, 2018).

Logo, o uso de aditivos associado ao volumoso extrusado, aliado ao adequado manejo nutricional, colabora para o controle de distúrbios metabólicos como acidose ruminal. Os aditivos podem melhorar a qualidade e aumentar a quantidade de nutrientes disponíveis na alimentação dos animais, melhorando, assim, a eficiência dos nutrientes absorvidos pelo animal, promovendo incremento aos parâmetros fisiológicos e comportamentais, podendo refletir no bem-estar animal (Oliveira et al., 2005).

Diante desse contexto, objetivou-se elucidar o potencial da utilização de volumoso extrusado contendo diferentes aditivos, sobre o consumo, comportamento e parâmetros fisiológicos de ovinos.

\section{Materiais e métodos}

O experimento foi realizado nas dependências do setor de ovinos e caprinos da Universidade Federal de Uberlândia, localizada no município de Uberlândia MG. As coordenadas geográficas do local do experimento são $18^{\circ} 30^{\prime}$ de latitude sul e $47^{\circ} 50^{\prime}$ de longitude oeste de Greenwich com altitude de $863 \mathrm{~m}$. O clima da região é tropical de altitude, com inverno ameno e seco e estação seca e chuvosa bem definida. O período de realização do experimento foi do dia 24 de outubro de 2017 a 25 de novembro de 2017. O mesmo foi aprovado pelo CEUA Comissão de Ética na Utilização de Animais, sob o número de protocolo 092/16.

O experimento foi dividido em duas fases de 15 dias, sendo os dez primeiros dias referentes à adaptação do animal à dieta e a gaiola metabólica e os outros cinco dias, dedicados à coleta de dados. Ao final da primeira fase os animais foram trocados de tratamento, e logo em seguida realizada nova adaptação e posterior coleta de dados referente à segunda fase.

Foram utilizadas vinte ovelhas não gestantes cruzadas (1/2 Dorper x 1/2 Santa Inês), com idade maior igual a quatro anos e peso corporal médio de $68 \mathrm{~kg}+/$ - 2,9. Os animais foram alojados em gaiolas metabólicas equipadas com piso ripado, coletor de fezes e urina, cocho, saleiro e bebedouro (padronizadas de acordo com o Instituto Nacional de Ciência e Tecnologia - INCT). Foram pesadas no início e final do período experimental, para obtenção da média do peso vivo e peso metabólico $\left(\mathrm{PV}{ }^{0,75}\right)$. As ovelhas foram vermifugadas antes do início do período experimental com monepantel via oral e verificada sua condição de mucosas oculares e realização do OPG.

Os animais receberam cinco tratamentos contendo volumoso extrusado com diferentes aditivos, sendo eles: óleos essenciais (Foragge ${ }^{\circledR}$ Essential $^{\circledR}$ ), Virginiamicina ${ }^{\circledR}$ (Foragge ${ }^{\circledR}$ Max $^{\circledR}$ ), tanino (Foragge ${ }^{\circledR}$ Bypro $^{\circledR}$ ), levedura inativa não purificada (Foragge ${ }^{\circledR} \mathrm{AA}$ ) e levedura inativa purificada (Foragge ${ }^{\circledR}$ Factor $^{\circledR}$ ). O Foragge ${ }^{\circledR}$ é um volumoso extrusado, produzido a partir de forragens 
Oliveira, K. A. et al.

do gênero Urochloa e enriquecido em sua composição nutricional de minerais, vitaminas, amido e dos aditivos testados. O referido volumoso utilizado tem por escopo substituir parcial ou totalmente a dieta de ruminantes quando se usa principalmente a silagem de milho como volumoso. A composição de cada tratamento se encontra na tabela 1 .

Tabela 1 - Composição bromatológica dos diferentes tipos de Foragge ${ }^{\circledR *}$

\begin{tabular}{cccccc}
\hline $\begin{array}{c}\text { Nutriente } \\
(\%)\end{array}$ & $\begin{array}{c}\text { Óleos } \\
\text { Essenciais }\end{array}$ & Virginiamicina & Tanino & $\begin{array}{c}\text { Levedura inativa não } \\
\text { purificada }\end{array}$ & $\begin{array}{c}\text { Levedura inativa } \\
\text { purificada }\end{array}$ \\
\hline MS & 90,0 & 90,0 & 90,0 & 90,0 & 90,0 \\
PB & 7,2 & 7,1 & 7,0 & 7,2 & 7,2 \\
FDN & 42,2 & 42,3 & 44,7 & 42,3 & 42,3 \\
FDA & 26,3 & 26,3 & 29,8 & 26,3 & 26,3 \\
EE & 1,9 & 2,0 & 1,6 & 1,9 & 2,0 \\
MM & 3,7 & 3,7 & 3,9 & 3,7 & 3,7 \\
NDT & 55,7 & 55,8 & 61,2 & 55,8 & 55,7 \\
Amido & 25,5 & 25,5 & 25,4 & 25,4 & 25,5 \\
Aditivo & $0,55 \%$ & $30 \mathrm{mg} \mathrm{kg}$ & $0,2 \%$ & $0,2 \%$ & $0,2 \%$ \\
\hline
\end{tabular}

MS: matéria seca; PB: proteína bruta; FDN: fibra em detergente neutro; FDA: fibra em detergente ácido; EE: extrato etéreo; MM: matéria mineral; NDT: nutrientes digestíveis totais. *Dados fornecidos pela fabricante Nutratta.

A dieta foi fornecida aos animais duas vezes ao dia na quantidade de $3,5 \%$ do peso corporal, especificamente às 08:00 e às 16:00, sendo composta pelo volumoso extrusado Foragge ${ }^{\circledR}$ com diferentes aditivos, água e sal mineral para ovinos (ad libitum). Quanto à aferição de consumo, foram realizadas pesagens diárias com balança com precisão de cinco gramas, tanto da dieta, como das sobras de cada animal. Essas foram mensuradas e sempre que os valores foram iguais à zero, aumentou-se a quantidade fornecida até atingir sobra equivalente a $10 \%$ do ofertado.

O cálculo do consumo de matéria seca (CMS) dos alimentos foi obtido por meio da diferença do ofertado em relação às sobras. As fezes na matéria natural foram pesadas diariamente em balança com precisão de cinco gramas em intervalos de 24 horas. As amostras de sobras e fezes de cada animal, ao final do período de colheita, foram homogeneizadas e formadas amostras compostas, para posteriores análises bromatológicas e cálculo do consumo e digestibilidade da matéria seca e dos nutrientes.

Após o final do período de coleta, as amostras de sobras e fezes eram armazenadas em freezers horizontais a $-15^{\circ} \mathrm{C}$, para conservação dos nutrientes. Posteriormente foi realizada a pré-secagem das amostras em estufa de circulação forçada de ar, a $55^{\circ} \mathrm{C}$ por 72 horas, até obter peso constante. Executado o procedimento as amostras foram trituradas, em moinho de facas do tipo Willey, em partículas de $1 \mathrm{~mm}$. Logo após, as amostras foram levadas ao laboratório onde foi determinada a matéria seca das amostras de sobras e fezes, em estufa a $105^{\circ} \mathrm{C}$ por 24 horas, sendo então calculada a matéria seca definitiva das mesmas e teor dos nutrientes, e posteriormente, a digestibilidade aparente dos nutrientes e matéria seca através das seguin-

tes equações (Eq. 1 e 2; Maynard et al., 1984):

$$
\begin{gathered}
C N=(\text { Cons } \times \% \text { cons })-(\text { Sob } \times \% \text { sob })(\text { Eq. } 1) \\
D A=\frac{C N-F M S}{C N} \times 100(\text { Eq. } 2)
\end{gathered}
$$

Onde: $\mathrm{CN}=$ consumo do nutriente $(\mathrm{kg})$; Cons = quantidade de alimento ofertado (kg); \%cons = teor do nutriente no alimento ofertado (\%); $\mathrm{Sob}=$ quantidade de sobra retirada $(\mathrm{kg}) ; \%$ sob $=$ teor do nutriente nas sobras (\%); DA = digestibilidade aparente (\%); FMS = quantidade de fezes na matéria seca $(\mathrm{kg})$.

Foram analisados no laboratório de nutrição animal (LABAN) os nutrientes: fibra em detergente neutro (FDN), fibra em detergente ácido (FDA) e fibra em detergente neutro corrigido para cinzas (FDNc), de acordo com metodologia descrita por Van Soest (1994). Através dos teores dos nutrientes, foi possível calcular consumo de matéria seca (CMS, kg/dia), com a diferença entre ofertado e sobras, consumo de matéria seca em função peso corporal (CMS/PC, \%), consumo de matéria seca em função do peso metabólico (CMS/PM, kg/PC ${ }^{0,75}$ ), digestibilidade da matéria seca (DMS, \%), consumo de FDN (CFDN, kg/dia) e digestibilidade de FDN (DFDN, $\%)$.

A avaliação do comportamento ingestivo ocorreu no último dia do experimento, foi realizada em 24 horas, sendo que a cada cinco minuto os animais foram observados quanto ao tempo em ruminação (Rum), ócio (Oc) ou ingestão (Ing) em min dia ${ }^{-1}$. O somatório do tempo gasto 
Oliveira, K. A. et al.

com ingestão e ruminação foi utilizado para calcular o tempo de mastigação total (Mast) em min dia-1.
A eficiência alimentar foi calculada dividindo-se o consumo de matéria seca por tempos em horas de ingestão, ruminação e mastigação, seguindo as seguintes formulas (Equações 3, 4 e 5):

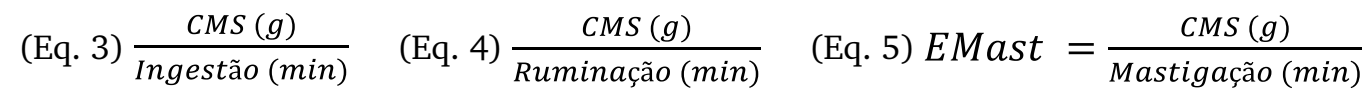

Onde: EIng = Eficiência de ingestão em gramas de matéria seca por minuto; ERum = Eficiência de Ruminação em gramas de matéria seca por minuto; EMast = Eficiência de Mastigação em gramas de matéria seca por minuto.

Os parâmetros fisiológicos frequência respiratória (FR), frequência cardíaca (FC), temperatura retal (TR) e movimentos ruminais (MR) foram aferidos com os animais dentro da gaiola de metabolismo, essas aferições foram durante 2 dias alternados no período de coleta, sempre ás 14:00, e posteriormente foi média desses valores para resultado final. As variáveis frequência respiratória (FR) e frequência cardíaca (FC) foram avaliadas conforme Borges, Silva e Carvalho (2018), a FR foi avaliada por contagem dos movimentos respiratórios por minuto (mov. $\min ^{-1}$ ), mediante a observação direta dos movimentos do flanco esquerdo. A frequência cardíaca, em batimentos por minuto (bat.min ${ }^{-1}$ ), foi obtida com a utilização de estetoscópio posicionado entre o terceiro e quarto espaço intercostal, à altura da articulação costocondral, durante um minuto. Na sequência, foi avaliada a temperatura retal por meio de termômetro digital até o disparo do sonorizador. Os movimentos ruminais (MR), movimentos em cinco minutos (mov. $5 \mathrm{~min}^{-1}$ ) foram obtidos com a utilização de estetoscópio posicionado no flanco esquerdo do animal. Todos os parâmetros fisiológicos foram aferidos uma vez por dia, às 14 horas, em 2 dias alternados por semana.

Utilizou-se o delineamento em blocos casualizados, com cinco tratamentos e oito repetições, blocando o efeito de fase. As médias dos tratamentos foram comparadas pelo teste SNK (Student-Newman-Keuls), com nível de significância de $5 \%$ de probabilidade. $\mathrm{O}$ programa estatístico utilizado foi SAEG 9. Para todas as variáveis foram testadas a normalidade e homogeneidade dos dados.

As variáveis climáticas, como temperatura, ambiente e umidade relativa foram registradas na Estação Meteorológica Capim Branco (Tabela 2), situado na Latitude: $18^{\circ} 52^{\prime} 52,5^{\prime}$ 'S e Longitude: 48²0'37,3”.

Tabela 2 - Temperatura e Umidade Relativa do ar referente ao período experimental

\begin{tabular}{cccc}
\hline \multicolumn{2}{c}{ Temperatura do ar $\left({ }^{\circ} \mathrm{C}\right)$} & \multicolumn{2}{c}{ Temperatura do ar $\left({ }^{\circ} \mathrm{C}\right)$} \\
\hline Máximo & Mínimo & Média & Média \\
27,80 & 18,92 & 22,61 & 79,89 \\
\hline
\end{tabular}

Dados obtidos da Estação Meteorológica da Fazenda Capim Branco - UFU.

Para análise de $\mathrm{pH}$ ruminal foram utilizadas cinco ovelhas não gestantes, cruzadas, com idade superior a quatro anos e peso corporal médio de $68 \mathrm{~kg}$, fistuladas no rúmen. Os animais foram distribuídos aleatoriamente em quadrado latino $5 \times 5$ (cinco períodos e cinco repetições); cada período teve duração de 15 dias (dez dias iniciais para adaptação e cinco últimos dias para coleta de dados e amostras). Os animais foram alojados em gaiolas metabólicas conforme citado anteriormente e receberam os tratamentos contendo volumoso extrusado com diferentes aditivos, sendo eles: óleos essenciais (Foragge $^{\circledR}$ Essential $^{\circledR}$ ), Virginiamicina ${ }^{\circledR}$ Foragge $^{\circledR}$ Max $^{\circledR}$ ), tanino (Foragge ${ }^{\circledR}$ Bypro ${ }^{\circledR}$ ), levedura inativa não purificada (Foragge $^{\circledR}$ AA) e levedura inativa purificada (Foragge ${ }^{\circledR}$ Factor $^{\circledR}$ ). A alimentação foi oferecida às 8:00 e as 20:00 nos dias de coleta de líquido ruminal. O experimento aconteceu concomitante ao citado anteriormente.

As coletas foram realizadas 2 vezes na semana, nos horários: 8:00, 10:00, 12:00, 14:00, 16:00, 18:00 e 20:00. Após a abertura da cânula o líquido ruminal era homogeneizado e coletado as respectivas amostras, com uso de uma mangueira(20 $\mathrm{cm}$ de comprimento e $1,9 \mathrm{~cm}$ de diâmetro), em que o líquido ruminal era alojado em uma vasilhame plástico (capacidade para $500 \mathrm{~mL}$ ) e imediatamente determinado o valor de $\mathrm{pH}$, com medidor eletrônico devidamente calibrado.

Para dados referentes aos valores de $\mathrm{pH}$ utilizou-se o quadrado latino, com cinco tratamentos e cinco repetições. As médias dos tratamentos foram comparadas pelo teste SNK (Student-Newman-Keuls), com nível de significância de $5 \%$ de probabilidade. O programa estatístico utilizado foi SAEG 9. Para todas as variáveis foram testadas a normalidade e homogeneidade dos dados.

\section{Resultados e Discussão}

Não se observou diferença estatística em função da inclusão de aditivos, para consumo de matéria seca em kg dia ${ }^{-1}$ (CMS), digestibilidade de matéria seca (DMS), consumo de fibra em detergente neutro (CFDN) e digestibilidade de fibra em detergente neutro (DFDN) (Tabela 3). Um dos fatores que pode influenciar o con- 
Oliveira, K. A. et al.

sumo dos alimentos é a relação volumoso/concentrado na dieta de ruminantes. Nesse experimento não houve variação dessas proporções entre os tratamentos, uma vez que todos os animais consumiram o mesmo alimento Foragge ${ }^{\circledR}$, variando somente o aditivo. Entretanto, quando se considera o CMS em função de peso corporal (CMS/ PC) e peso metabólico (CMS/PM) encontrou-se diferença estatística entres os tratamentos, sendo que a levedura inativa purificad (LINP) a propocionou maior consumo.

Tabela 3 - Efeito da inclusão de diferentes aditivos sobre os parâmetros nutricionais de ovinos

\begin{tabular}{ccccccc}
\hline Tratamento & CMS & CMS/PC & CMS/PM & DMS & CFDN & DFDN \\
\hline Óleos Essenciais & 2,24 & $3,58 \mathrm{AB}$ & $100,65 \mathrm{AB}$ & 57,43 & 1,21 & 44,97 \\
LINP & 1,76 & $2,49 \mathrm{~B}$ & $72,34 \mathrm{~B}$ & 53,96 & 0,87 & 45,30 \\
LIP & 2,54 & $4,13 \mathrm{~A}$ & $115,67 \mathrm{~A}$ & 53,46 & 1,21 & 44,05 \\
Virginiamicina & 1,84 & $2,81 \mathrm{AB}$ & $80,05 \mathrm{AB}$ & 52,45 & 1,02 & 49,40 \\
Tanino & 1,94 & $2,83 \mathrm{AB}$ & $81,54 \mathrm{AB}$ & 52,36 & 1,09 & 44,35 \\
\hline Média & 2,07 & 3,18 & 90,31 & 53,97 & 1,07 & 45,52 \\
Coeficiente de variação & 31,04 & 33,16 & 32,37 & 11,34 & 31,22 & 15,56 \\
P-Valor & 0,1253 & 0,0253 & 0,0355 & 0,0455 & 0,2816 & 0,6113 \\
\hline
\end{tabular}

LINP: levedura inativa não purificada; LIP: levedura inativa purificada; CMS: consumo de matéria seca em $\mathrm{kg} \mathrm{dia}^{-1}$; CMS/PC: consumo de matéria seca em função do peso vivo em \%; CMS/PM: consumo de matéria seca em função do peso metabólico $\left(\mathrm{g} \mathrm{kg}^{-1} 0,75\right.$ dia $\left.^{-1}\right)$; DMS: digestibilidade da matéria seca em \%; CFDN: consumo de fibra em detergente neutro $\mathrm{kg} \mathrm{dia}^{-1}$; DFDN: digestibilidade de fibra em detergente neutro \%; Médias seguidas de letras maiúsculas na coluna diferem pelo teste de SNK $(\mathrm{P}<0,005)$.

Segundo Manuel (2016), o uso de peso metabólico (PM) é mais eficaz para expressar o consumo, pois é uma forma de expressar o metabolismo de energia como base na expressão de requerimento de mantença. Os animais que receberam a levedura inativa purificada tiveram os maiores CMS/PC e CMS/PM. Contudo, o uso da levedura não purificada promoveu os menores valores de consumo da matéria seca (CMS/PC e CMS/PM). É possível observar que a inclusão de levedura inativa purificada aumentou em aproximadamente 58\% o CMS PC em relação ao tratamento com a levedura inativa não purificada. A purificação permite a caracterização estrutural e funcional da levedura, já que o processo retira contaminantes. Outro fator importante a ser considerado é que o processo de purificação aumenta a padronização e qualidade ao produto (Assis, 2019).

A levedura favorece a digestão e o aproveitamento dos nutrientes, o que eleva o consumo, pois provoca aumento na taxa de degradação da fibra, especialmente em dietas ricas em concentrado (Pires, 2012). Logo, infere-se que a ração com levedura inativa purificada pode ter favorecido a colonização de partículas alimentares, acelerando o crescimento de bactérias celulolíticas, melhorando a eficiência da degradabilidade dos nutrientes pelas bactérias ruminais, aumentando a taxa de consumo.

Independentemente do tratamento aplicado, todos os animais que receberam o alimento Foragge ${ }^{\circledR}$ tiveram o CMS superior (em média) $1,02 \mathrm{~kg} \mathrm{dia}^{-1}$ ao recomendado pelo NRC (2007) para essa categoria $(1,05$ $\left.\mathrm{kg} \mathrm{dia}^{-1}\right)$, o que equivale a uma superioridade de $97 \% \mathrm{em}$ relação ao NRC (2007). De acordo com Mertens (1997), os mecanismos de controle que podem limitar o consumo são: densidade energética e teor de fibra das dietas. Zanine e Macedo Junior (2006) relatam que a presença de fibra de baixa qualidade pode limitar a consumo de matéria seca. Assim, é possível concluir que os teores FDN do alimento em questão não foi o limitante para o consumo de matéria seca, visto que os animais consumiram quase 2 vezes o recomendado NRC (2007).

A suplementação com aditivos na alimentação de ruminantes tem-se mostrado promissora visto o aumento da ingestão e da digestão de alimentos (Morais, 2011). Quanto à digestibilidade da matéria seca (DMS), essa não apresentou variação estatística (Tabela 3), mesmo com o aumento do CMS/PC e CMS/PM, a mesma se manteve constante. De maneira geral quanto tem-se aumento no consumo de matéria seca observa-se redução na digestibilidade da matéria seca (Zanine e Macedo Junior, 2006). Isso não foi observado nesse estudo, o que pode mostrar que a extrusão e os aditivos mantiveram a DMS em níveis estáveis, sugerindo melhor aproveitamento na fermentação ruminal. Os aditivos são utilizados com o propósito de melhorar ambiente ruminal. Segundo Doreau et al. (2003), a principal causa da variação na digestibilidade da dieta é o tempo de retenção de partículas no rúmen. Dessa forma, o aumento do consumo (Tabela 3) levaria ao aumento na taxa de passagem e consequente diminuição na digestibilidade. Entretanto, não foi observado esse comportamento nesse estudo.

O produto Foragge ${ }^{\circledR}$ foi desenvolvido para ser semelhante a silagem de milho e assim poder substituir a mesma na dieta dos ruminantes. Segundo Valadares Filho (2006) a composição química média da silagem de milho produzida no Brasil encontrada na literatura 
Oliveira, K. A. et al.

é de 7,18\% de PB; 2,79\% de EE; 53,98\%; FDN e de $29,49 \%$ de FDA e digestibilidade da matéria seca de $59,58 \%$. Valores esses semelhantes aos encontrados no presente trabalho, para o produto Foragge ${ }^{\circledR}$ (tabelas $1 \mathrm{e}$ 3 ), principalmente referente a digestibilidade de 55,38 $\%$, sugerindo possível substituição da silagem de milho pelo Foragge ${ }^{\circledR}$. Com a vantagem desse produto permitir maior consumo como evidenciado na tabela 3 e maior matéria seca em sua composição bromatológica (tabela 1).

Quanto às variáveis consumo de fibra em detergente neutro (CFDN) e digestibilidade de fibra em detergente neutro (DFDN) essas não apresetaram diferenças estatísticas. Segundo Zanine e Macedo Júnior (2006), a concentração de FDN na dieta influencia negativamente o CMS, em função da fermentação mais lenta e de maior tempo de permanência no rúmen. Contudo, a maior digestibilidade da fibra pode estimular o consumo pelo aumento da taxa de passagem. Segundo Mertens (1997) o CFDN para ruminante deve ser de 0,8 a $1,2 \% \mathrm{PV}$, nesse experimento a média geral de CFDN foi de $1,07 \%$, dentro do recomendado pela literatura. O consumo de FDN não limitou o CMS neste trabalho, uma vez que o CMS encontrado estava acima do recomendado (NRC 2007, para essa categoria $1,05 \mathrm{~kg} \mathrm{dia}^{-1}$, tabela 3 ), o que pode ser explicado pela capacidade de melhor digestibilidade do alimento extrusado enriquecido por aditivos. Os valores de digestibilidade da fibra em detergente neutro (DFDN) se mantiveram iguais estatisticamente. A ideia do produto Foragge ${ }^{\circledR}$ é substituir a silagem de milho, assim Valadares Filho (2006) cita que a DFDN da silagem de milho é de $48,77 \%$ em média. No presente estudo a DFDN ficou em $45,52 \%$ em média, valor inferior em $6,60 \%$, o que podemos considerar como pequena diferença.

Não se observou efeito do uso de volumoso extrusado com diferentes aditivos, no comportamento ingestivo dos animais (Tabela 4). O tempo de ruminação é influenciado pela natureza da dieta, visto que a ruminação é proporcional aos níveis de FDN dos volumosos (Van Soest, 1994). De acordo com Oliveira (2018), alimentos processados, como alimento peletizado e extrusado, reduzem o tempo de ruminação, enquanto volumoso com alto teor de parede celular aumentam o tempo de ruminação.

Tabela 4 - Efeito da inclusão de diferentes aditivos sobre o comportamento ingestivo de ovinos

\begin{tabular}{cccccccc}
\hline Tratamento & ING & RUM & ÓCIO & MST & EFING & EFRUM & EFMAST \\
\hline Óleos Essenciais & 206,87 & 94,37 & 1093,75 & 346,25 & 11,49 & 54,01 & 6,86 \\
LINP & 226,25 & 49,37 & 1168,12 & 271,87 & 8,23 & 57,44 & 6,49 \\
LIP & 185,00 & 113,2 & 1141,87 & 298,12 & 14,83 & 31,77 & 9,93 \\
Virginiamicina & 169,28 & 42,85 & 1227,85 & 212,14 & 11,23 & 50,50 & 8,63 \\
Tanino & 212,50 & 63,75 & 1163,75 & 276,25 & 11,02 & 39,06 & 7,56 \\
\hline Média & 200,79 & 73,46 & 1157,30 & 282,69 & 11,63 & 46,45 & 7,87 \\
Coeficiente de variação & 28,64 & 34,97 & 8,09 & 33,10 & 34,18 & 39,66 & 37,98 \\
P-Valor & 0,3402 & 0,0784 & 0,1162 & 0,1162 & 0,1650 & 0,6138 & 0,1663 \\
\hline
\end{tabular}

ING: ingestão (min dia-1); RUM: ruminação (min dia $\left.{ }^{-1}\right)$; MAST: mastigação (min dia-1); EFING: eficiência de ingestão (g min $\left.{ }^{-1}\right)$; EFRUM: eficiência de ruminação $\left(\mathrm{g} \mathrm{min}^{-1}\right)$; EFMAST: eficiência de mastigação $\left(\mathrm{g} \mathrm{min}^{-1}\right)$; Médias seguidas de letras maiúsculas na coluna diferem pelo teste de SNK $(\mathrm{P}<0,005)$. LINP: levedura inativa não purificada; LIP: levedura inativa purificada;

O produto extrusado Foragge ${ }^{\circledR}$ acrescido de diferentes aditivos, proporcionou comportamento alimentar similar entre os animais, visto que suas propriedades bromatológicas são similares. Estes resultados podem ser explicados pelo fato de as dietas terem níveis semelhantes de nutrientes, principalmente de FDN (Tabelas 1) e mesmo tamanho de partícula do volumoso $(2 \mathrm{~mm})$. Contudo, vemos que numericamente o tempo em ruminação variou muito entre os tratamentos. Verificando a tabela 3, observa-se que essa variação também foi vista nos dados de CMS/PC e CMS/PM, uma vez que a ruminação é uma função diretamente ligada ao cosnumo de matéria seca. Segundo Van Soest (1994), o tamanho da partícula pode influenciar o valor nutricional do alimento, pois afeta tanto o consumo de matéria seca quanto a retenção ruminal, exercendo efeito sobre as atividades de ruminação e mastigação.

Observou-se que os animais gastaram em média 73,46 minutos com ruminação, 200,79 minutos com ingestão, 1157,30 minutos em ócio e 282,69 minutos com mastigação. É possível perceber que os animais gastaram pouco tempo com ruminação, ingestão e maior tempo em comportamento de ócio e mastigação, independente do tratamento (Tabela 4). Essa discrepância nos valores encontrados para comportamento ingestivo pode ser justificada pelas características física do produto Foragge ${ }^{\circledR}$. Segundo Van Soest et al. (1991), o tempo de ruminação é influenciado pela natureza da dieta, cosnumo de matéria seca e teor de parede celular do volumoso. No entanto, provavelmente devido a presença de aditivos tamponan- 
Oliveira, K. A. et al.

tes, não foi observado queda de $\mathrm{pH}$ ruminal (Tabela 5), ou redução na digestibilidade do alimento (Tabela 3 ).

De acordo com Van Soest et al. (1991), a atividade de ruminação em animais adultos dura cerca de oito horas por dia com variações entre 4 e 9 horas. Esse comportamento alimentar é influenciado principalmente pela natureza da dieta, ou seja, quanto mais concentrada a dieta, ou mais processado o alimento, menor é o tempo gasto com ruminação. Assim, podemos veirifcar que o tempo gasto com ruminação foi bem abaixo da recomendação. Contudo, não foi observado nenhum problema ruminal, como pode ser eveidenciado pelos dados contidos nas tabelas 3, 4 e 5 .

Quanto maior o comportamento de ócio, maior a economia de energia e essa será direcionada a maior produção animal (Young, 1987). Com relação ao tempo gasto com ingestão, animais confinados gastam em torno de uma hora consumindo alimentos com elevada densidade energética, ou até mais de seis horas, para fontes com baixo teor de energia. É possível perceber que todos os tratamentos gastaram menor tempo com alimentação, esse fato é justificado pela maior eficiência de ingestão garantida pela dieta (Tabela 4).
Os dados de eficiência de ingestão, ruminação e mastigação foram estatisticamente iguais entre os tratamentos (Tabela 4). A ausência de efeito observada nas atividades citadas anteriormente pode estar também relacionada com a aproximação entre a composição química das dietas (Tabela 1), em que os tamanhos das partículas dos alimentos apresentaram semelhanças, visto que seu processamento foi o mesmo para todas as dietas experimentais. Contudo, todos os valores encontrados para eficiência de ingestão, ruminação e mastigação foram maiores do que os encontrados na literatura (Oliveira, 2018).

Os valores sobre parâmetros fisiológicos, frequência respiratória (FR), frequência cardíaca (FC) e temperatura retal $(\mathrm{T})$ não foram influenciados pela utilização aditivos (Tabela 5). Os valores de FC e T se mantiveram dentro dos valores recomendados para a espécie (Cunningham e Charlotte, 1999). Entretanto, o parâmetro FR mostrou-se acima dos valores de referência proposto por

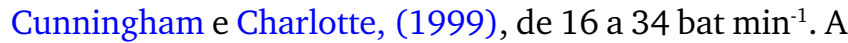
alteração na FR pode ser consequência das altas temperaturas registradas no mês de novembro $\left(\sum=27,80^{\circ} \mathrm{C}\right)$, associada a elevada umidade relativa do ar (URA), que apresentou média de 79,89\% (Tabela 2).

Tabela 5 - Efeito da inclusão de diferentes aditivos sobre os parâmetros fisiológicos de ovinos

\begin{tabular}{cccccc}
\hline Tratamento & MR & FR & FC & T & pH \\
\hline Óleos Essenciais & $4,12 \mathrm{C}$ & 49,25 & 68,50 & 38,77 & 6,31 \\
LINP & $5,62 \mathrm{AB}$ & 60,75 & 68,00 & 38,88 & 6,45 \\
LIP & $4,25 \mathrm{C}$ & 65,00 & 74,25 & 38,97 & 6,3 \\
Virginiamicina & $5,71 \mathrm{~A}$ & 59,71 & 72,85 & 38,77 & 6,38 \\
Tanino & $4,75 \mathrm{BC}$ & 56,00 & 64,00 & 38,76 & 6,3 \\
\hline Média & 4,87 & 58,10 & 69,33 & 38,83 & 6,35 \\
Coeficiente de variação & 18,30 & 27,40 & 15,49 & 0,81 & 10,90 \\
P-Valor & 0,0019 & 0,3720 & 0,3788 & 0,5912 & 0,1852 \\
\hline
\end{tabular}

MR: Movimentos ruminais ( $\left.\operatorname{mov} 5 \mathrm{~min}^{-1}\right)$; FR: frequência respiratória (mov $\left.\min ^{-1}\right)$; FC: frequência cardíaca (batimentos min $\left.{ }^{-1}\right)$; T: temperatura retal $\left({ }^{\circ} \mathrm{C}\right)$; Médias seguidas de letras maiúsculas na coluna diferem pelo teste de SNK $(\mathrm{P}<0,005)$. LINP: levedura inativa não purificada; LIP: levedura inativa purificada;

Os efeitos do estresse térmico para os animais dependem da capacidade do animal para adaptar-se, sendo que a zona de conforto térmico para ovinos situa-se entre 20 e $30^{\circ} \mathrm{C}$. Quanto a URA a zona de conforto de ovinos adultos encontrava-se entre 50 e $80 \%$ (Baêta e Sousa, 2010). Assim pode-se dizer que a temperatura estava dentro dos limites para conforto térmico, porém, a URA estava próximo ao limite máximo proposto para conforto térmico, podendo justificar o aumento da FR, durante experimento. Outro fator a ser considerado é o horário de avaliação desses parâmetros, sendo feito sempre às 14:00, horário considerado de maiores temperaturas.
A susceptibilidade de ovinos ao estresse por calor aumenta na medida em que o binômio umidade relativa e temperatura ambiente ultrapassa a zona de conforto térmico; essa condição dificulta a dissipação de calor e incrementa a temperatura corporal, e os mecanismos termorregulatórios são acionados aumentando a perda de calor de forma insensível através da sudorese e respiração (Borges et al. 2018). Segundo mesmo autor, a taxa de respiração pode quantificar a severidade do estresse pelo calor, e que uma frequência respiratória de 40- 60, $60-80,80^{-1} 20 \mathrm{mov} \mathrm{min}^{-1}$ caracteriza, respectivamente, um estresse baixo, médio-alto e alto para os ruminantes. Para os ovinos, 200 é classificado como severo. Logo, pode-se dizer que os animais se encontravam em estresse térmico 
Oliveira, K. A. et al.

moderado, visto que o CMS, DMS e CFDN (Tabela 3) não foram prejudicados, pelo contrário, ficaram acima do recomendado pelo NRC (2007).

Houve diferença entre os tratamentos para MR $(\mathrm{P}<0,05)$, sendo que o tratamento com levedura inativa purificada e óleos essenciais, apresentaram menor valor de movimentação ruminal (Tabela 5). Entretanto, mesmo com a menor movimentação ruminal, o pH do rúmen se manteve dentro dos valores de referência (Tabela 5). O tratamento com virginiamicina, foi detentor do maior valor de movimentação ruminal juntamente com a levedura inativa não purificada, provavelmente esse apresentou maior tempo de permanência no rúmen. Sabe-se que a movimentação ruminal é estímulo para a ruminação, no entanto os valores de ruminação foram iguais em todos os tratamentos. Assim, podemos inferir que os aditivos testados promoveram eficiência microbiana e com isso contribuindo para manutenção do ph ruminal em valores de estabilidade. Os valores encontrados para movimento ruminal apresentaram média de $0,96 \mathrm{mov} \mathrm{min}^{-1}$. Segundo Marques et al. (2007), são considerados normais de 1 a 3 movimentos min $^{-1}$ de ruminação.
Não se observou diferença estatística entre os tratamentos sobre o pH ruminal (Tabela 5), que se manteve dentro dos valores de referência considerado como ótimo (6,0 e 7,0) (Mould et al., 1983). Vários fatores interferem no $\mathrm{pH}$ ruminal, como a forma física da dieta, o tamanho da partícula, a composição da dieta e o processamento do alimento (Mould et al., 1983). O alimento volumoso Foragge ${ }^{\circledR}$ possui $25 \%$ de amido. Logo, os animais consumiram aproximadamente $518 \mathrm{~g} \mathrm{dia}^{-1}$ de amido, porém o pH se manteve estável, uma vez que esse fato poderia acarretar distúrbios acidogênicos. No entanto a presença de aditivos no produto Foragge ${ }^{\circledR}$ contribuiu para estabilização do $\mathrm{pH}$ ruminal e possivelmente para o equilíbrio microbiano no rumem.

Houve efeito quadrático sobre o $\mathrm{pH}$ quando avaliado o horário de coleta de líquido ruminal (Gráfico 1). Os menores valores de $\mathrm{pH}$ ruminal aqui encontrados foram nas primeiras 4 horas após a refeição, uma vez a fermentação ruminal do alimento acidifica o rúmen com formação de ácidos graxos voláteis. Segundo Van Soest (1994), após alimentação há um aumento da produção de ácidos graxos voláteis e queda nos valores de $\mathrm{pH}$, seguido de redução lenta ao longo do dia com restabelecimento próxima à nova alimentação.

Gráfico 1 - Efeito do uso de diferentes aditivos sobre o pH ruminal de ovinos em função do horário de coleta

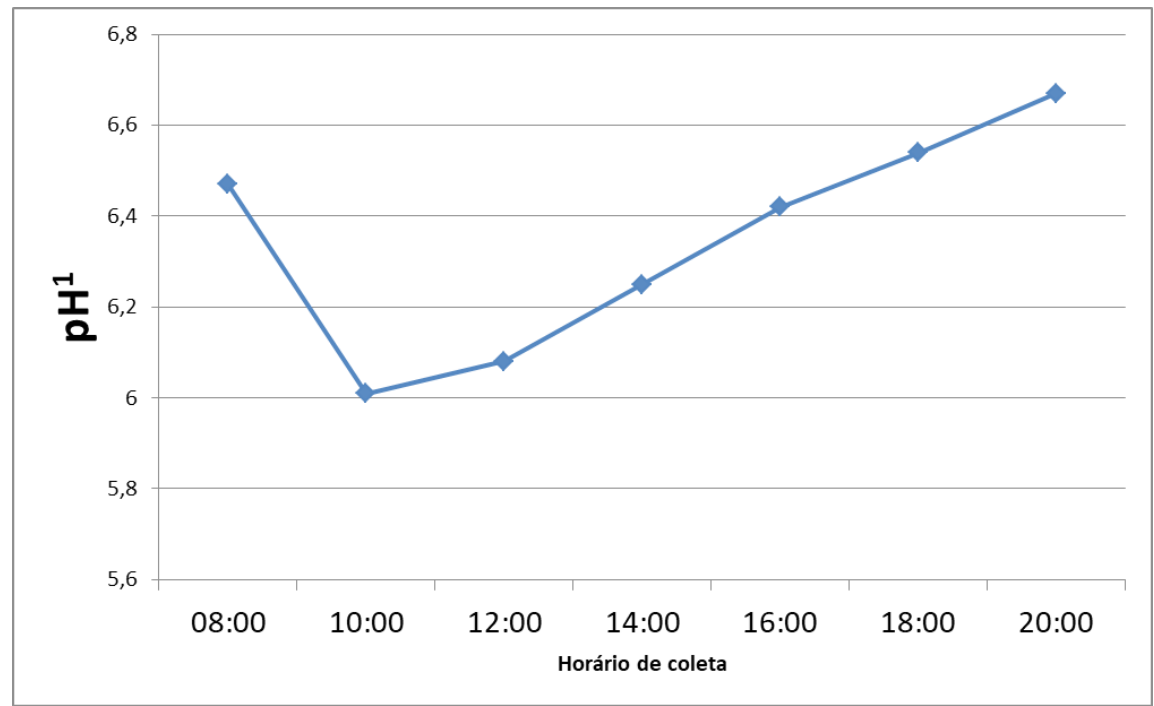

$1 \mathrm{Y}=7,561095-0,2299099 \mathrm{X}+0,009486 \mathrm{X} 2, \mathrm{R} 2=74,12 \%$. P-valor $=0,0024$

É possível perceber que mesmo após a alimentação os valores de $\mathrm{pH}$ não ultrapassaram os valores de referência (6,0; Mould et al., 1983). A estabilidade ruminal proporcionada pelos aditivos está associada à inibição do crescimento de bactérias produtoras de ácido láctico, à menor perda de energia metabolizável ao diminuírem a produção de metano, e à menor queda de $\mathrm{pH}$ ruminal, permitindo maior eficiência no aproveitamento dos nutrientes (Oliveira et al., 2020).

\section{Conclusão}

O uso de aditivos no presente trabalho influenciou o consumo pelas ovelhas, sendo o produto Foragge ${ }^{\circledR}$ Factor ${ }^{\circledR}$ (levedura inativa purificada) o de maior valor. De maneira geral todos os aditivos foram eficientes nas variáveis analisadas, especialmente na manutenção do $\mathrm{pH}$ ruminal, consumo de matéria seca e digestibilidade aparente da matéria seca. 


\section{Referências}

Assis, T. S. 2019. Utilização de volumoso extrusado contendo diferentes aditivos na alimentação de ovinos. Uberlândia: Universidade Federal de Uberlândia, 72f. Dissertação de Mestrado. doi: http://dx.doi. org/10.14393/ufu.di.2019.1219.

Baêta F. C.; Souza C. 2010. Ambiência em edificações rurais: conforto ambiental. Editora UFV, Viçosa, MG, Brasil.

Borges, J. O.; Silva, A. P. V.; Carvalho, R. A. 2018. Conforto térmico de ovinos da raça Santa Inês confinados com dietas contendo três níveis de inclusão de concentrado. Boletim De Indústria Animal, 75: 1-7. doi: https://doi.org/10.17523/bia.2018.v75.e1410.

Cunningham, R.; Charlotte, C. B. 1999. Common variable immunodeficiency: clinical and immunological features of 248 patients. Clinical immunology, 92: 34-48. doi: https://doi.org/10.1006/ clim.1999.4725.

Doreau, M.; Michalet-Doreau, B.; Grimaud, P.; Atti, N.; Nozière, P. 2003. Consequences of underfeeding on digestion and absorption in sheep. Small Ruminant Research, 49: 289-301. doi: https://doi.org/10.1016/ S0921-4488(03)00145-7.

Manuel, M. 2016. Estudo do peso metabólico e índice de Kleiber na estimação de parâmetros genéticos de características ponderais em uma população de bovinos de raça Brahman. Dracena: Universidade Estadual Paulista "Júlio de Mesquita Filho", 83f. Dissertação de mestrado. Disponível em: http://hdl.handle.net/11449/138132.

Marques, J. D. A.; Ito, R. H.; Zawadzki, F.; Maggioni, D.; Bezerra, G. D. A.; Pedroso, P. H. B.; Prado, I. N. D. 2007. Comportamento ingestivo de tourinhos confinados com ou sem acesso à sombra. Campo Digital, 2: 43-49. Disponível em: http://revista2.grupointegrado.br/revista/ index.php/campodigital/article/view/313.

Maynard, L. A.; Loosli, J. K.; Hintz, H. F.; Warner, R. G. 1984. Nutrição animal. 3. ed. Rio de Janeiro: F. Bastos, RJ, Brasil.

Mertens, D. R. 1997. Creating a system for meeting the fiber requirements of dairy cows. Journal of dairy science, 80: 1463-1481. doi: https:// doi.org/10.3168/jds.S0022-0302(97)76075-2.

Morais, J. A. S.; Berchielli, T. T.; Reis, R. A. 2011. Aditivos. In: Berchielli, T. T.; Pires, A. V.; Oliveira, S. G., eds. Nutrição de Ruminantes, Editora Funep, Jaboticabal, SP, Brasil.

Mould, F. L.; Ørskov, E. R.; Shirley, A. G. 1983. Associative effects of mixed feeds. II. The effect of dietary addition of bicarbonate salts on the voluntary intake and digestibility of diets containing various proportions of hay and barley. Animal Feed Science and Technology, 10: 31-47. doi: https://doi.org/10.1016/0377-8401(83)90004-4.
NRC - Nutrient Requirements of Small Ruminants: Sheep, Goats, Cervids, and New World Camelids. 2007. National Academy of Science, Washintgton, D.C., USA.

Oliveira, J. S.; ZANINE, A. M.; SANTOS, E. M. 2005. Uso de aditivos na nutrição de ruminantes. Revista Eletrônica de Veterinária, 6: 1-24. Disponível em: http://www.veterinaria.org/revistas/redvet/n111105. html.

Oliveira, K. A. 2018. Ração extrusada com diferentes relações volumoso: concentrado para ovinos em crescimento. Uberlândia: Universidade Federal de Uberlândia, 92 f. Dissertação de mestrado. doi: http:// dx.doi.org/10.14393/ufu.di.2018.783.

Oliveira, K. A.; Macedo Júnior, G. L.; Araújo, C. M.; Sousa, L. F.; Araújo, M. J. P.; Siqueira, M. T. S. 2020. Different roughage to concentrate ratios in extruded ration and metabolic parameters of growing lambs. Semina: Ciências Agrárias, 41: 1653-1666. doi: http://dx.doi.org/10.5433/16790359.2020v41n5p1653.

Pires, L. C. B. 2012. Utilização de leveduras na alimentação de ruminantes. Cadernos de Pós-Graduação da FAZU, 2: 1-8. Disponível em: http://www.fazu.br/ojs/index.php/posfazu/article/view/459.

Souza, A. A.; Rodrigues, S. A. 2012. Atividade antimicrobiana do óleo essencial de Rhaphiodon echinus (NEE \& MART) SHAUER. Revista de Biologia e Farmácia, 7: 12-17. Disponível em: http://sites.uepb.edu. br/biofar/download/v7n2-2012/atividadeantimicrobiana.pdf.

Valadares Filho, S. C. 2006. Tabelas brasileiras de composição de alimentos para bovinos. UFV.

Van Soest, P. V.; Robertson, J. B.; Lewis, B. A. 1991. Methods for dietary fiber, neutral detergent fiber, and nonstarch polysaccharides in relation to animal nutrition. Journal of Dairy Science, 74: 3583-3597. doi: https://doi.org/10.3168/jds.S0022-0302(91)78551-2.

Van Soest, P. J. 1994. Nutritional ecology of the ruminant. 2.ed. Cornell University Press, Ithaca, NY, USA.

Young, B. A. 1987. The effect of climate upon intake. Anais do Simpósio Internacional de Nutrição de Herbívoros, Londres, Reino Unido.

Zanine, A. M.; Macedo Junior, G. L. 2006. Importância do consumo da fibra para nutrição de ruminantes. Revista Eletrónica de Veterinária, 7:1-11. Disponível em: https://www.researchgate.net/publication/26439858 Importancia_do_consumo_da_fibra_para_nutricao_de_ruminantes Importance_of_consume_of_fiber_for_nutrition_of_ruminant. 